\title{
A Case Report of Signet-Ring Cell Carcinoma Colon
}

\author{
Ritesh Kohli, Surinder Singh, Ashwani K Gupta, Prithpal Singh Matreja
}

\begin{abstract}
We report a case of 14-year-old male coming to the emergency department with acute intestinal obstruction. Exploratory laparotomy shows an annular stenosing growth in the descending colon. Resection and anastomosis of descending colon with defunctioning right transverse colostomy is performed followed by chemotherapy with 5-fluorouracil (5-FU) which ensured survival of the patient without metastatic disease even after 6 months of the treatment.

Despite the reported high malignant behavior and poor prognosis of such tumors, prompt effective surgical and chemotherapeutic management may increase the chances of survival of such patients.
\end{abstract}

Keywords: Signet-ring cell carcinoma, Colon carcinoma, Colon, Resection.

How to cite this article: Kohli R, Singh S, Gupta AK, Matreja PS. A Case Report of Signet-Ring Cell Carcinoma Colon. J Postgrad Med Edu Res 2013;47(3):153-155.

Source of support: Nil

Conflict of interest: None declared

\section{INTRODUCTION}

Signet-ring cell carcinoma (SRCC), a unique subtype of mucin-producing adenocarcinoma, ${ }^{1}$ where the nuclei is pushed to one side as component cells retain abundant intracytoplasmic mucin, hence giving the cells their characteristic histological appearance. ${ }^{2}$ Stomach, breast and colon account for more than $90 \%$ cases of SRCC. ${ }^{1}$ SRCC is quite uncommon in rectum and colon with the reported incidence ranging from 0.1 to $0.9 \% .^{3,4}$ SRCC in colon is notorious for its diffuse intramural infiltration, with lymph node involvement and peritoneal surface metastasis, ${ }^{1}$ and behaves more aggressively than carcinoma of other histological types. ${ }^{3,4}$ As symptoms usually appear late, SRCC is detected at an advanced stage ${ }^{3,4}$ and majority of patient are in the 6th or 7th decade of life. ${ }^{2}$ Though there have been reports of cases less than 40 years of age ${ }^{3}$ SRCC has a malignant biological behavior and an extremely poor prognosis. $^{2}$

We, report here a case of SRCC in a 14-year-old male patient reporting to the emergency department.

\section{CASE REPORT}

A 14-year-old male patient reported to the emergency department with a history of generalized pain abdomen with distension for 5 days. The patient also had a complaint of constipation and bilious vomiting for the past 3 days. Patient gave a history of appendicectomy performed 6 months back and there was no other relevant history.

Physical examination showed patient to be conscious, cooperative and oriented to time, place and person. The patient was afebrile with pulse of 110 beats per minutes, blood pressure of 110/84 mm Hg and respiratory rate of 24 per minute. The patient had pallor.

Per abdominal examination showed a scar present on the right iliac fossa, abdomen was tense, tender and distended, no mass was felt and there were no bowel sounds. Per rectal examination revealed normal, nontender rectal mucosa with ballooning and no growth or fecalith were felt.

The complete blood count demonstrated a hemoglobin level of $8 \mathrm{gm} \%$ and a total leukocyte count of 12,050 per cubic mm (with $88 \%$ neutrophil and $10 \%$ lymphocytes). The blood urea and serum creatinine levels were with normal limits. The preoperative level of carcinoembryonic antigen (CEA) was $6 \mathrm{ng} / \mathrm{ml}$.

Plain X-ray of the abdomen showed multiple air fluid levels and ultrasonography demonstrated free fluid in Morrison's pouch, subhepatic region and left paracolic gutter.

An exploratory laparotomy was planned under general anesthesia, $500 \mathrm{ml}$ of serous fluid was present in the peritoneal cavity was sent for cytological examination. There were no metastatic deposits in the peritoneal cavity and on the surfaces of solid viscera of the abdomen.

An annular stenosing growth encompassing the whole circumference of descending colon was detected (Fig. 1). The biopsy was taken and sent for histopathological examination. Resection and anastomosis of $8 \mathrm{~cm}$ of

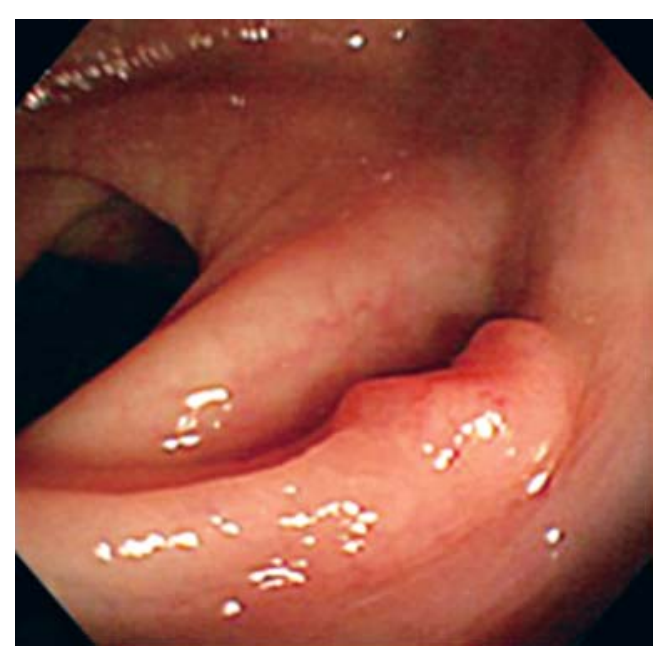

Fig. 1: Colonoscopy revealed a discolored, flat-elevated lesion with central depression, $7 \mathrm{~mm}$ in diameter 
descending colon including growth with defunctioning transverse colostomy was performed.

The postoperative period was uneventful and patient was started oral feeding from the second postoperative day. The histopathological examination showed signet ring cell and mucin adenocarcinoma, malignant neoplastic tissue infiltrating up to the serosal layer was observed (Figs 2 and 3). The fluid cytology showed hemorrhagic exudative effusion with mild lymphocytosis and florid mesothelial cell proliferation. There was no evidence of tuberculosis or malignancy. The postoperative CEA levels were $6 \mathrm{ng} / \mathrm{ml}$ after 1 week of surgery and $4 \mathrm{ng} / \mathrm{ml}$ after completion of 6 cycles of chemotherapy.

Chemotherapy was started with 5-fluorouracil (5-FU) $450 \mathrm{mg} / \mathrm{m}^{2}$ and leucovorin $100 \mathrm{mg} / \mathrm{m}^{2}$ for 5 days after every 4 weeks for 6 cycles. Follow-up for 6 months of chemotherapy and 6 months thereafter showed stable

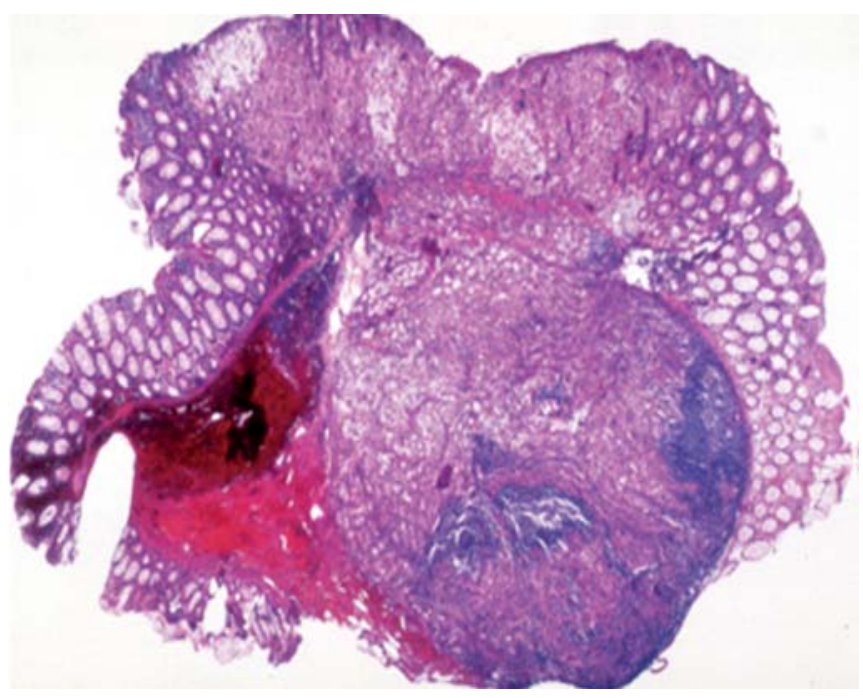

Fig. 2: Histological section shows signet-ring cell carcinoma that had deeply invaded into the submucosal layer

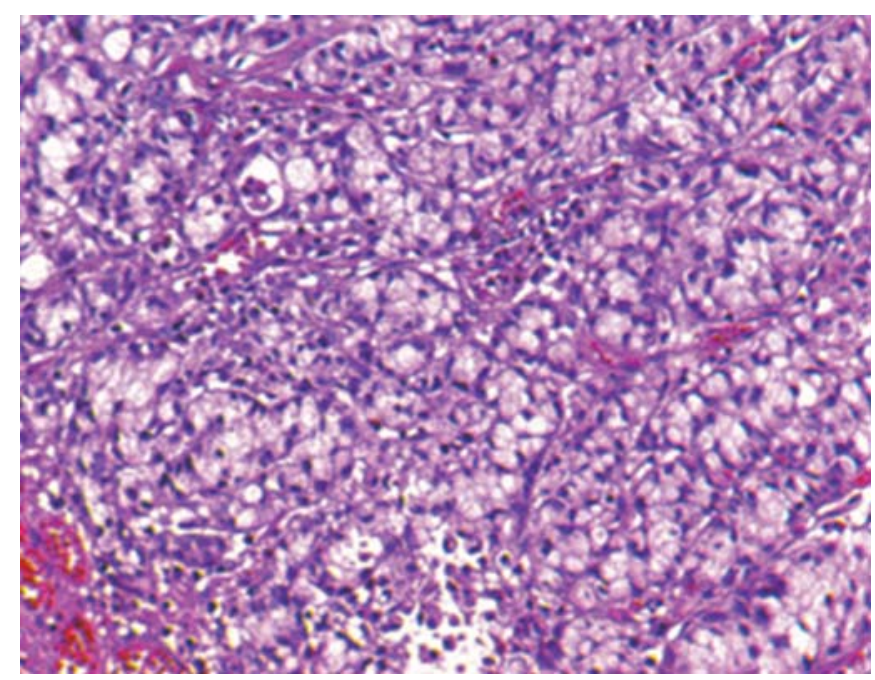

Fig. 3: Histological section shows the vertical cut end of the resected tumor which was positive for carcinoma cells general physical condition and no metastatic disease was demonstrated in ultrasonography.

\section{DISCUSSION}

Colorectal carcinoma in young has poor prognosis due to delay in diagnosis as it is associated with vague or unusual symptoms, rarity of disease and no general population screening, difficult natural history and biology (lack of dysplasia, adenoma); more frequent mucinous histology and inadequate treatment (inappropriate lymph node recovery and evaluation). ${ }^{5}$ Laufman and Safhir first described primary SRCC of the colon and rectum in $1951 .{ }^{6}$ The reported incidence is about $1 \%{ }^{2,7}$

More than 95\% of SRCC arises from the stomach ${ }^{1,4}$ and the rest in other organs including the colon, rectum, gallbladder, pancreas, urinary bladder and breast. ${ }^{4}$ SRCCs frequently metastasize to regional lymph nodes, peritoneal surfaces, the ovaries, and lung, regardless of the tissue of origin. ${ }^{1}$ Primary SRCC of colon and rectum is rare and follows an aggressive course with poor prognosis. ${ }^{3}$ Colorectal malignancies are extremely rare in pediatric age group; and have a very poor prognosis and usually beyond the scope of operative correction. The youngest recorded case is of a 9-month-old child. ${ }^{8}$ The poor prognosis is mainly attributed to delay in the diagnosis, advanced stage of the disease at presentation and poor histological differentiation of the malignancy. The predominant histological type in adolescents is the poorly differentiated mucinous adenocarcinoma whose prognosis is very poor. This histopathological type is known to be more aggressive with predisposition to early metastasis. ${ }^{9}$

Signet ring cell variant of mucinous adenocarcinoma is seen equally distributed in the right and left colon. Most of them are ulcerated and involve the full thickness of bowel wall. ${ }^{10}$ The patient may present as a case of acute intestinal obstruction with no preceding signs and symptoms or rarely with a perforation. But more commonly the patient presents with a long history of abdominal discomfort, diarrhea, constipation or a mass. Other complaints such as cachexia, weight loss, jaundice, ascites or amenorrhea, suggestive of metastatic disease are also commonly seen. ${ }^{2,10}$

SRCC has been associated with inflammatory bowel disease, with the reported association of $14 \%$, although, our patient did not have inflammatory bowel disease. ${ }^{11}$

In young patients, a high index of suspicion is required to assess the primary and the metastatic disease; to evaluate its operability and respectability. ${ }^{10}$ Nodal and metastatic disease can be present in $70 \%$ of patients at presentation. In SRCCs metastasis is more frequently to the peritoneal cavity, ovaries and lymph nodes. ${ }^{1,4,10}$ 
Combination of levamisole and 5-FU is considered to be the best form of chemotherapy, even for advanced SRCC. ${ }^{12}$ The estimated reduction of overall death rate with use of these agents is $33 \%{ }^{8}$ The overall prognosis of SRCC is extremely poor with most patients dying within the first year of diagnosis and peritoneal carcinomatosis. The 5-year survival rate is only $12 \% .^{12}$

\section{CONCLUSION}

The overall prognosis of the carcinoma of the colon and rectum in children will only improve with increased awareness leading to early diagnosis of the condition. A high level of suspicion coupled with a simple digital rectal examination followed by sigmoidoscopy and/or colonoscopy if required, can result in early diagnosis which well go a long way in providing effective therapy. Resection even palliative is always preferable to the bypass, because it effectively relieves the obstruction and also decreases the tumor load. Surgery should be the first modality of treatment as the disease in children responds poorly to chemotherapy as well to radiotherapy. The value of chemotherapy as a means of palliation has been controversial and responses have been less than optimal.

\section{REFERENCES}

1. Chu PG, Weiss LM. Immunohistochemical characterization of signet-ring cell carcinoma of the stomach, breast and colon. Am J Clin Pathol 2004;121:884-92.

2. Almagro UA. Primary signet-ring carcinoma of the colon. Cancer 1983;52:1453-57.

3. Jagtap SV, Nikumbh DB, Khirsagar AY, Jagtap SS, Khan S. Primary signet-ring carcinoma (Linitus Plastica) of the colorectum presenting as subacute intestinal obstruction. Online J Health Allied Sci 2012;11(1):14.

4. Fu KI, Sano Y, Kato S, et al. Primary signet-ring cell carcinoma of the colon at early stage: A case report and a review of literature. World J Gastroenterol 2006;12(21):3446-49.

5. What is a signet cell cancer? Cancer help UK. Cancer research UK. Available from: http://www.cancerresearchuk.org/cancer- help/about-cancer/cancer-questions/what-is-a-signet-cellcancer. (Last accessed: 15.12.2012).

6. Laufman H, Saphir O. Primary linitis plastica type of carcinoma of the colon. Arch Surg 1951;62:79-91.

7. Giacchero A, Aste H, Baracchini P, et al. Primary signet-ring carcinoma of the large bowel: Report of nine cases. Cancer 1985; 56:2723-26.

8. Tung SY, Wu CS, Chen PC. Primary signet-ring cell carcinoma of colorectum: An age-and sex-matched controlled study. Am J Gastroenterol 1996;91:2195-99.

9. Odone V, Chang L, Caces J, George SL, Pratt CB. The natural history of colorectal carcinoma in adolescents. Cancer 1982;49: 1716-20.

10. Anthony T, George R, Roudriguez-Bigas M, Petrelli NJ. Primary signet-ring cell carcinoma of the colon and rectum. Ann Surg Oncol 1996;3:344-48.

11. Ooi BS, Ho YH, Eu KW, Seow Choen F. Primary colorectal signet-ring cell carcinoma in Singapore. ANZ J Surg 2001;71: 703-06.

12. Laurie JA, Moertel CG, Fleming TR, et al. Surgical adjuvant therapy of large-bowel carcinoma: An evaluation of levamisole and the combination of levamisole and fluorouracil. J Clin Oncol 1989;7:1447-56.

\section{ABOUT THE AUTHORS}

\section{Ritesh Kohli}

Ex-Resident, Department of Surgery, Government Medical College and Rajindra Hospital, Patiala, Punjab, India

\section{Surinder Singh}

Former Professor and Head, Department of Surgery, Government Medical College and Rajindra Hospital, Patiala, Punjab, India

\section{Ashwani K Gupta}

Associate Professor, Department of Pharmacology, Gian Sagar Medical College, Patiala, Punjab, India

\section{Prithpal Singh Matreja (Corresponding Author)}

Associate Professor, Department of Pharmacology, Gian Sagar Medical College, Patiala, Punjab, India, e-mail: drpsmatreja@yahoo.co.in 